\title{
Analysis on the Interactive Relationship Between Honesty Culture Construction and Community Governance
}

\author{
Hongyuan $\mathrm{Xu}$ \\ School of Marxism \\ Dalian University of Technology \\ Dalian, China
}

\author{
Liansheng Yang \\ School of Marxism \\ Dalian University of Technology \\ Dalian, China
}

\begin{abstract}
The moral recessive tension of honest culture and the social governance attribute derived from cultural recessive power are the theoretical starting point for the interaction between honest culture construction and community governance. The logic of reality is honest culture construction to promote the improvement and optimization of community governance and community governance govern the implementation of the honest culture construction. To further promote the interactive development of the two, we need to start from three aspects. On the one hand, it is to build a community integrity culture governance pattern of joint construction and governance, on the other hand, it is the institutional guarantee for the interaction between sound community governance and honest culture construction, and the third aspect is the technical means of interaction between innovative community governance and honest culture construction.
\end{abstract}

Keywords-honest culture; culture construction; Chinese community governance; interactive relationship

\section{INTRODUCTION}

With the deepening of reform and opening-up and the development of market economy, China's economy and society have achieved remarkable development, but also exposed social problems such as the lack of honesty culture, which restricts the in-depth development of China. As the basic unit of social governance, the community is an important field to solve the problem of social honesty and build an honesty culture. Clarify the interactive relationship between the construction of honesty culture and community governance, clarify the theoretical starting point and practical logic of the interaction between the two, and promote the interactive development of the two, which is conducive to improving the weak honesty cultural and helping to achieve good governance in the community.

\section{THE THEORETICAL StARTING POINT OF THE INTERACTION BETWEEN HONEST CULTURE CONSTRUCTION AND COMMUNITY GOVERNANCE}

Honesty culture is the value concept and code of conduct formed by human beings in long-term social interaction activities. It is "comprehensiveness and collectively referred to as honesty thought, honesty moral, honesty concept, honesty system, etc." [1], with the social function of norms, guidance, encouragement and cohesion [2], is an important force for carrying out social activities, maintaining social relations, and aggregating social groups, is an important content and basic premise for the benign governance of grassroots communities. In the community governance, attach importance to the construction of honesty culture, transform the ethical attributes of traditional Chinese honest culture into governance attributes with modern significance; use the internal mechanism of morality and culture as the logical starting point to establish a good honesty system, to publicize honesty thought, to promote honesty morality, to rooted in the concept of good honesty, and to shape the honesty behavior. The purpose of these is to form an atmosphere of community honesty culture and promote the benign governance of the community.

The relationship between honesty culture construction and community governance is the interaction between premise and destination, means and purpose. The theoretical starting point is the moral recessive tension of honest culture and the social governance attribute derived from cultural recessive power. At the first level, the internalization of honesty culture is a social interaction that affects humanity through moral constraints. In social interaction, the culture of honesty is in a latent state, and it appears as a hidden tension with moral constraints in society [3]. When the actual conflict of interest isn't obvious, and the hidden tension develops to a certain extent, it will exert its own social integration function, promoting social interaction and cooperation, and regulating social order. However, when the actual conflict of interest is highlighted, even if the hidden tension does not develop to a certain extent, it will lead to the issue of integrity or credibility, disrupt the social order. At the second level, the culture of honesty influences people's way of life with the explicit forms of social discourse and argumentation system. "Culture is not only an intellectual and imaginative work, but fundamentally speaking; culture is still a holistic way of life. [4]" Honesty culture affects the formation of human values, interprets the meaning of human interaction, and shapes the human lifestyle, when manifested as lifestyle and communicative behavior; it has developed 
into a hidden power from self-identity, discipline, and influence. "This kind of implicit power is dispersed in the process of social life, becoming the inherent soft power of social stability, showing cultural nature and social will. [5]" At the third level, honesty culture plays a social governance function by improving public life order. The honesty culture construction helps to determine the moral orientation of people in public life and regulate the rights and obligations of people. It not only helps to regulate the life of the individual, but also helps to cultivate the honesty atmosphere of the group life, enhancing the orderly, stabling and predictable social development, and creating an orderly public life.

\section{THE REALISTIC LOGIC OF INTERACTION BETWEEN HONEST CULTURE CONSTRUCTION AND COMMUNITY GOVERNANCE}

The benign interaction between the construction of honesty culture and community governance is a complete system based on the internal development logic, to enhance the coupling degree and interaction quality of the two as a process, with the result of exerting the effectiveness of both parties. The realistic logic of interaction between the two parties is reflected in the construction of honesty and culture to promote the optimization and improvement of community governance, and community governance governing the implementation of the honest culture construction.

The honest culture construction promotes the optimization and improvement of community governance, which is mainly reflected in three levels: First, the honest culture construction provides motivation and vitality for improving community governance. When people communicate with each other in benign honesty, they can save communication costs and improve communication efficiency, help build a stable and orderly community integrity environment, and provide power support for community governance. A good community honesty environment will also mobilize and inspire the creativity of residents or groups to participate in community work, the enthusiasm of participating in community affairs, the enthusiasm of community activities, and the vitality of community good governance. Second, the honest culture construction helps to reduce or avoid conflicts in community governance. Strengthening the construction of credibility culture can renew the individual's honesty and trust, enhance the integrity concept of social organizations and help the multi-subjects of social activities to consciously and consciously follow the integrity of morality to conduct social interactions, regulate their own behaviors, and reduce conflicts in community governance. By combining the honesty order at the national and regional levels with the social credit system, we will unite multiple departments and organizations within the community to build a joint incentive mechanism for joint trustworthiness and untrustworthiness. Improve the default cost of untrustworthy personnel, improve the disciplinary system for untrustworthy personnel, and establish a value-oriented approach based on honesty to avoid conflicts in community governance. Third, the honest culture construction ensures the orderly and efficient community governance. Through the education and propaganda of the honesty culture matches up the establishment of the integrity system, implements stricter ethical requirements for the subject and content of community governance, gives full play to the functional attributes of the community, and ensures orderly community governance. Rely on the resources and advantages of the community to establish a social risk identification and early warning mechanism. Conduct social risk investigations for different groups, units and systems in the community, focus on key populations and key industries, quickly capture relevant information on social risk identification, and quickly launch early warning mechanisms when risks are triggered to ensure efficient community governance.

Community governance governing the implementation of the honest culture construction is mainly reflected in three levels: First, the essence of community governance determines the goal of building a culture of integrity. The honest culture construction is an important content and component of community governance and its goal depends on the essential attributes of social governance. "The path choice of community governance should be consistent with the development process of the community itself and the community's attributes, which is the basic premise for improving community governance.[6]"By clarifying the essential attributes of community attributes and community governance, and complying with the development rules of community and community governance, we can establish a viable goal of building a honesty culture. Second, community governance provides institutional guarantee for the honest culture construction. Through community governance, formulate corresponding institutional mechanisms, clarify the rights and responsibilities of various departments, levels, and groups, establish reward and punishment mechanisms to restrict the behavior of residents and groups, and provide substantive carriers for the honest culture construction to translate traditional theory into social reality. Third, community governance promotes multidimensional collaborative participation in the honest culture construction. As the administrative thinking moves from "management" to "governance", the government functional departments play more service development coordination functions in public affairs. This kind of transformation can help the community residents reach a understanding and consensus on the honesty culture and participate in the development of the honest culture construction.

\section{THE ENHANCED PATH OF INTERACTION BETWEEN HONEST CULTURE CONSTRUCTION AND COMMUNITY GOVERNANCE}

"Honesty to promote governance, governance to build honesty." Taking the honesty culture construction as a breakthrough and innovation of community governance, innovative governance thinking translates the ethical value of honesty culture into community governance norms, reform governance path, promoting the construction of integrity culture. To achieve the above objectives, it is needed to start from the following three aspects. 
First, build a community-based cultural governance structure that is common construction, common governance and sharing. First, we must make full use of community advantages, integrate community resources, and establish a safeguard system for multi-subjects to participate in community governance, and encourage and mobilize relevant social forces to join the community honesty culture construction team. Secondly, in view of the diversity and complexity of the community, it is necessary to divert and accurately guide different groups, different industries and different personnel, and enhance the effectiveness of community residents' participation in the honesty culture construction. Finally, it is necessary to protect the achievements of the community's honesty culture construction, realize the development results shared by the community residents, so that the residents can enjoy the real benefits from the honesty culture construction.

Second, improve the institutional guarantee for the interaction between community governance and honest culture construction. First, the government departments should issue guidance documents on community governance and honesty culture construction, carry out top-level design and macro-planning for the development of the relationship between the two. Secondly, the legislative department should improve the relevant laws on the construction of community honesty culture, and guide people to attach importance to the self-construction of honesty thought through legal means. Finally, the community management department should establish corresponding honesty culture construction and guarantee systems for different communities, maintain the benign interaction and common development of community governance and honesty culture construction.

Third, innovate the technical means to interact between community governance and honesty culture construction. In the context of the development of information technology and big data, combine the big data technology and honest culture construction. Through the establishment of a data management platform for honesty construction, the honesty data of residents and shops in the community will be collected, analyzed and processed, and an honest electronic file and supporting joint reward and punishment mechanism of honesty individual will be established. Provide convenient services within the jurisdiction of honesty. Through relevant early warning mechanisms, relevant departments and organizations within the joint community will implement joint punishment for untrustworthy residents. Promote the digitalization, precision and individualized development of community governance through the integration of online and offline, virtual and reality, government governance and multi-dimensional collaboration.

\section{CONCLUSION}

The honesty culture construction requires the government to lead and social forces to participate in the governance, highlighting the diversity of governance subjects and the diversity of governance methods. The honesty culture construction as the key path of grassroots community governance is an innovation of diversified social governance in the field of morality and culture. The interactive innovation between the two will promote the effective integration of the two and achieve the goal of benign governance.

\section{REFERENCES}

[1] Cai Weiping, XieHongzhong. The historical origin of honest culture and the contemporary honesty culture construction [A]. See: Fujian Province Yanhuang Culture Research Association, Conference Proceedings of Research on "Honesty Culture Construction and the Great Rejuvenation of the Chinese Nation" [C]. Fuzhou: Fujian Yanhuang Culture Research Association, 2013: 84. (in Chinese)

[2] Lin Xinglan. Practical Thinking on the of Contemporary Honesty Culture Construction[J].Socialism Studies,2007(6):45. (in Chinese)

[3] Gao Juwen. Honesty: As an implicit tension in the integration of society [J]. Theory and Reform, 2007 (1): 123. (in Chinese)

[4] Raymond Williams. Culture and Society: 1780-1950 [M], translated by Gao Xiaoling. Jilin: Jilin Publishing Group Co., Ltd., 2011:337. (in Chinese)

[5] Li Shan. Theoretical logic and action path of community culture governance [M]. Beijing: Higher Education Press, 2017: 123-124, 209. (in Chinese)

[6] Sun Ping. The Development Path of China's Community Governance: Diversified Co-governance under the Leadership of the Party and Government[J]. Cass Journal of Political Science, 2018(1): 107. (in Chinese) 